\title{
Cephalometric evaluation of Brahmins of Kathmandu, Nepal based on Jarabak's analysis
}

\section{Pokharel $\mathrm{M}^{1}$, Shrestha $\mathrm{SL}^{2}$}

'Mona Pokharel, Senior Resident; Department of Orthodontics, College of Dental Surgery, B.P. Koirala Institute of Health Sciences, Dharan, Nepal; ${ }^{2}$ Situ Lal Shrestha, Professor; Nepalese Army Institute of Health Sciences, Kathmandu, Nepal.

\begin{abstract}
Background: The cephalometric norms derived from Caucasian population shows a great degree of variation when applied to different population.

Objectives: The present research was performed with the objective of determining cephalometric norms of Brahmins of Nepal based on Jarabak's analysis, to evaluate the variability between male and female and to compare the cephalometric norms with Caucasians.

Methodology: Lateral cephalogram of 108 non-growing patients which consisted of 63 females and 45 males of Nepalese Brahmins who met our inclusion criteria were traced manually. Thirteen craniofacial parameters of Jarabak's analysis were measured.

Results: The comparison between Brahmin populations of Nepal with the Caucasian population showed statistically significant difference in ten out of thirteen parameters. The comparison between Nepalese male Brahmins and female Brahmins showed that there were statistically significant differences in eleven out of thirteen parameters.

Conclusion: It can be concluded that there exists sexual and ethnic dimorphism in craniofacial features. The findings of the study highlight the fact that Brahmin population is significantly different from Caucasian population. Females presented with smaller craniofacial variable than male when gender comparison was performed among Nepalese Brahmins male and female. This research has helped to generate knowledge and understanding of craniofacial features of Nepalese Brahmins and derived norms for orthodontic diagnosis and treatment planning.
\end{abstract}

Key words: Jarabak's analysis; Lateral cephalometric radiographs; Norms.

DOI: https://doi.org/10.3126/jkmc.v8i1.25263

\section{INTRODUCTION}

Cephalometry is not a new entity in orthodontics.

Cephalometric analysis has been described for almost 90 years as one of the most essential tool in diagnosing and planning treatment in Orthodontics ${ }^{1}$. It can also be used to assess the growth pattern in the craniofacial complex and to provide a clinical tool for the study of malocclusion and underlying skeletal disproportion, the vertical and horizontal relationship of a jaw to the cranial base and to each other, and the relationships of the teeth to their supporting bone ${ }^{2}$. Many analyses were introduced between 1946 and $1985^{3}$.

\section{Address for correspondence}

Dr. Mona Pokharel

Senior Resident, Department of Orthodontics, College of Dental Surgery

B.P. Koirala Institute of Health Sciences, Dharan, Nepal

E-mail: pokharel_mona@yahoo.com
Most of the cephalometric analyses were performed in Caucasians and those values were used as a reference value in diagnosing and treating cases of individuals of different ethnic groups ${ }^{4,5}$.Various cephalometric studies have proven that the 'norms' should be based on ethnic, sex and age differences for better clinical evaluation ${ }^{6,7}$. As the morphologic features of different races and ethnic groups exist in a certain geographic location which indicates that the facial morphology is influenced by culture, climate, and geographic boundaries ${ }^{8-11}$. According to 2011 Nepal census, Brahmins are the second most populous group with $12.2 \%$ of Nepal's population. A large number of this population resides in Kathmandu valley with a population of 410,126 (23.5\%). The number of studies for the Brahmins of Nepal is limited so far. At present, there is no published Nepalese Brahmins cephalometric norms using Jarabak analysis ${ }^{12}$. So, it becomes imperative to derive cephalometric 
norms for this major group of population which remains unknown till now.

Knowing their cephalometric values would help to best treat these groups according to the individual facial characteristics. The purpose of this study is therefore to determine cephalometric norms for Brahmins of Nepal using Jarabak's analysis and to compare these individuals with Caucasians as well as to compare the differences between sexes. As there is a large ethnic variation, it is unscientific to use or apply cephalometric norms specific to one racial group on a different population. Jarabak's cephalometric analysis is based on Bjork analysis. This analysis considers vertical inter-maxillary relationships and uses cranial base as reference. This analysis provides ample information about craniofacial morphology of a patient with the use of only a few cephalometric measurements.

\section{METHODOLOGY}

A hospital based cross sectional study was conducted in Peoples' Dental College \& Hospital, Kathmandu from January 2016 to December 2016. A non-probability convenience sampling technique was done over a period of six months to obtain an adequate sample of 108 lateral cephalographs ( 63 female, 45 male).

The samples included in this study were ethnic Brahmins traced back to three generations, age of the subjects ranged from 18-27 years ${ }^{13}, 14$, overjet and overbite not exceeding more than $2-4 \mathrm{~mm}$ with little or no incisor crowding or rotations, full complement of permanent teeth in proper occlusion, except third molars, acceptable facial profile ${ }^{15}$ and a good quality of cephalometric radiographs ${ }^{16}$. Subjects excluded from the study were patients who had previous history of orthodontic treatment or orthognathic surgery, apparent skeletal or dental deformity, history of craniofacial disorder or trauma, missing teeth except $3^{\text {rd }}$ molar, pregnant females and subject not giving consent.

A written informed consent was taken from each participant. Ethical clearance was obtained from Institutional Review Board, Institute of Medicine, Kathmandu. Standardized digital lateral cephalometric radiographs were taken in Dental Imaging Center, Kathmandu, Nepal. The radiographs were taken in natural head position with teeth in maximum intercuspation and lips in light contact. To standardize the method, all the radiographs were taken from the same cephalometric unit in a standardized way by the radiographic technician and were verified by principal researcher. All the lateral radiographic cephalograms were later traced and measured by the principal researcher.

Determination of error involved during landmark locations and tracing of cephalogram was done by retracing twenty five radiographs after one month. The comparison of measurements of two groups were made statistically by applying Dahlberg's formula. The data used in the study for Caucasians was obtained from the original values obtained by Joseph R. Jarabak and James A. Fizzell, popularly known as Jarabak analysis ${ }^{12}$. Thirteen craniofacial parameters of Jarabak's analysis ${ }^{12}$ were measured and tabulated using Statistical Package for the Social Sciences (SPSS) version 17.0 for further analysis. The continuous variables were summarized with the help of mean, standard deviation, standard error of mean and range. Comparison of mean values within the ethnic group on the basis of sex and between Nepalese Brahmins and Caucasians to test for statistical significant difference was done with the help of independent $t$ test. The level of significance was set at $5 \%$.

\section{RESULTS}

A total of 13 parameters were studied for cephalometric evaluation through Jarabak's analysis in the study done among 108 Nepali Brahmins. Six linear measurements, a proportional measurement and six angular measurements were evaluated. The mean values of linear measurements of Jarabak's analysis between Brahmin males and females showed that on an average the values of Sella-Nasion,Sella-Articulare, ArticulareGonion, Gonion-Menton, Sella-Gonion, Nasion-Menton of females is less than the males $(p<0.001)$. The Jarabak $\%$ is also higher in males as compared to females $(p<0.001)$ (Figure 1).

The mean values of the angular parameters of males and females of the study population for saddle angles and upper gonial angles were similar between both the sexes with $p=0.610$ and $p=0.306$ respectively. However, the values for articular angle $(p=0.012)$, lower gonial angle $(p<0.001)$ were higher for females. As a result, both total gonial angle $(p=0.001)$ and the sum of angles $(p<0.001)$ were higher for Brahmin females compared to males (Figure 2).

The mean value of anterior cranial base (S-N) for Caucasians was significantly higher $(p<0.001)$ than Nepalese while the mean value of posterior cranial base (S-Ar) was higher for the Nepalese Brahmin $(p<0.001)$ study population. The mean values of Ramus height 
(Ar-Gon), Anterior facial height (N-Me) and Jarabak $\%$ for Nepalese Brahmins was significantly higher $(p<0.001)$ than the Caucasian populations. There was no statistically significant difference $(p>0.05)$ in the mean values for Mandibular body length (Gon-Me) and Posterior facial height (Se-Gon) between Nepalese and Caucasian populations (Table 1).

The mean Saddle angle of the Nepali Brahmins was significantly higher $(p<0.001)$ than the Caucasian populations with mean difference of $2.282 \mathrm{~mm}$. Regarding the gonial angles, there was no difference in the mean values of the lower gonial angle between the two groups $(p=0.683)$ while mean values of upper $(p=0.001)$ and total gonial angle $(p<0.001)$ is significantly higher among the Caucasians compared to Nepalese Brahmins. The Caucasians also had significantly higher $(p<0.001)$ mean values for the sum of three angles compared to Nepalese with the mean difference of 5.194 (Table 2).

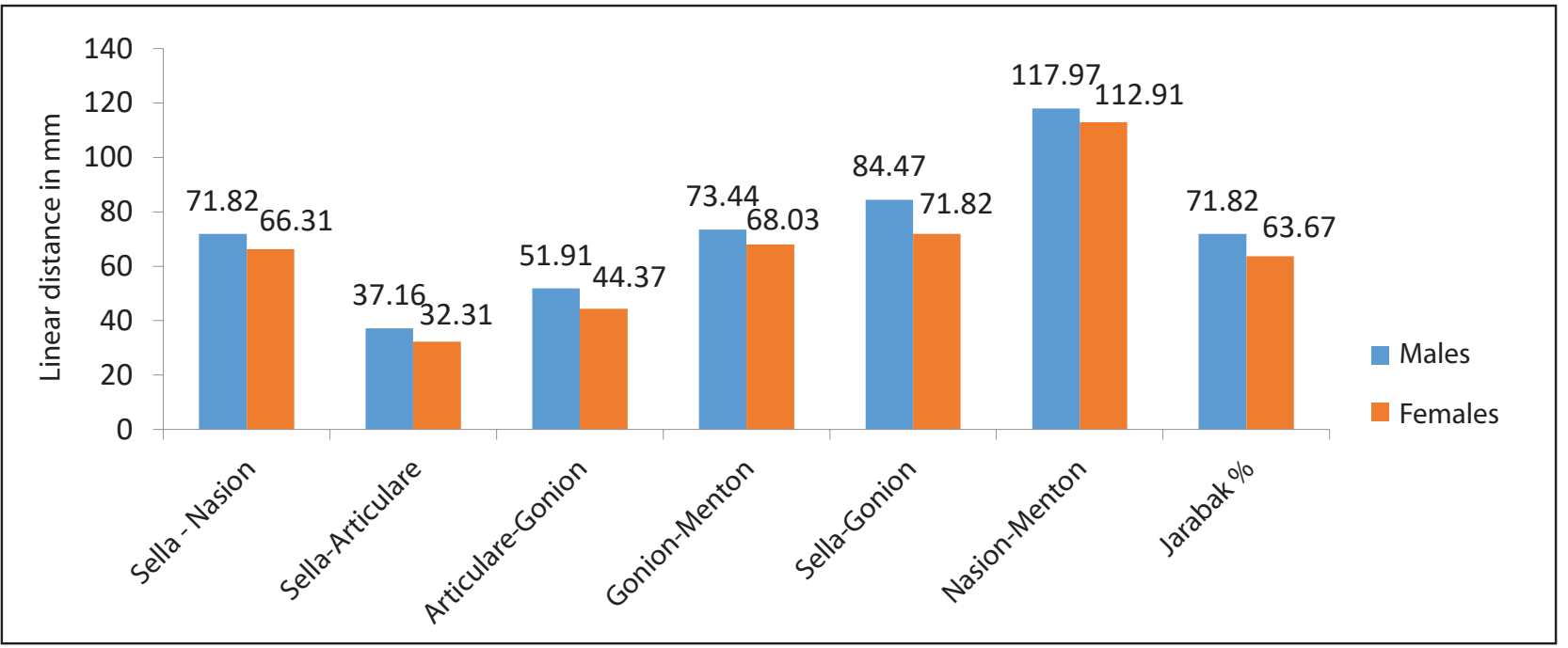

Figure 1: Sex wise mean values of linear measurements in Nepalese Brahmins

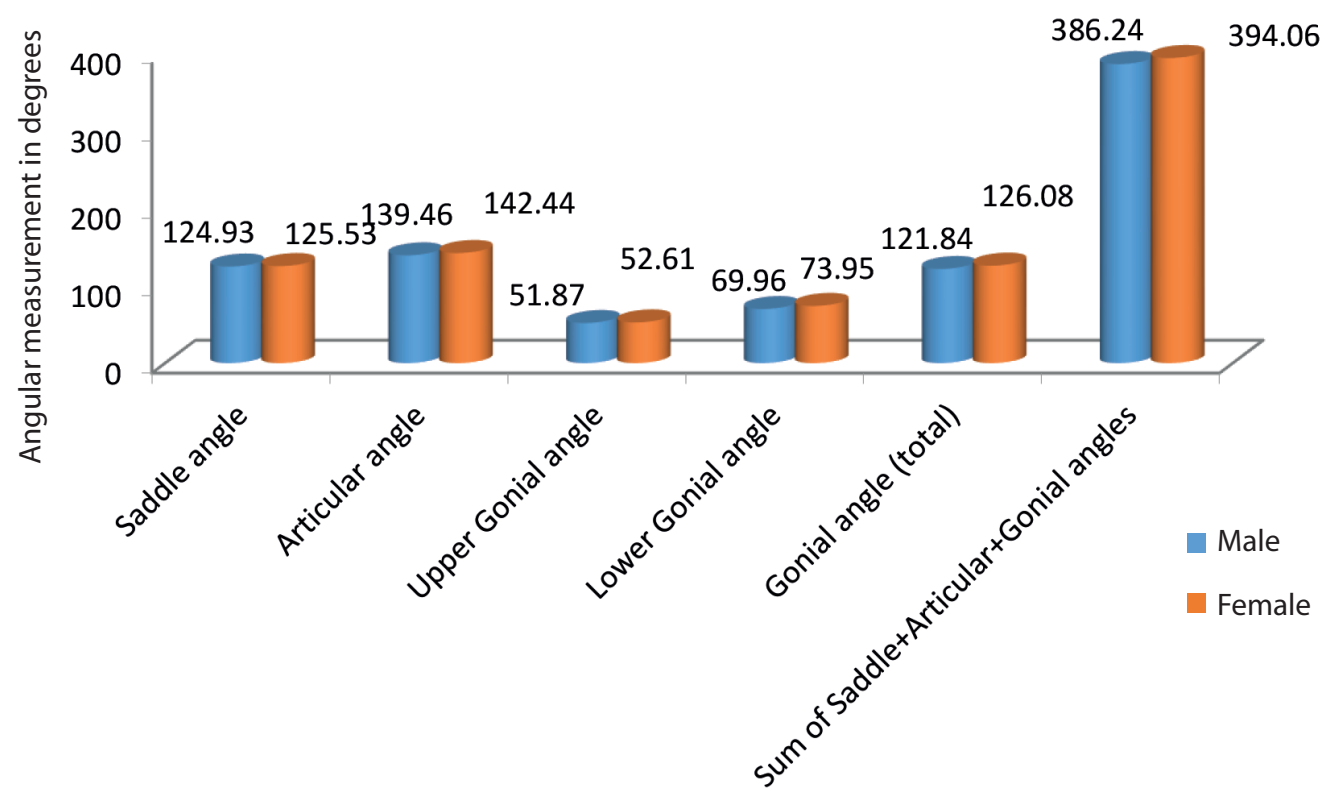

Figure 2: Sex wise mean angular measurements of Jarabak's analysis 
Table 1: Comparison of mean linear measurements between Nepalese and Caucasian populations

\begin{tabular}{|c|c|c|c|c|c|c|}
\hline \multirow{2}{*}{$\begin{array}{l}\text { Linear Measurements } \\
\text { of Jarabak's analysis }\end{array}$} & \multirow{2}{*}{$\begin{array}{c}\text { Nepalese } \\
\text { (Mean士SD) }\end{array}$} & \multirow{2}{*}{$\begin{array}{l}\text { Caucasians } \\
\text { (Mean士SD) }\end{array}$} & \multirow{2}{*}{ Mean Diff. } & \multicolumn{2}{|c|}{$\mathbf{9 5 \%}$ Confidence Interval } & \multirow{2}{*}{ p-value } \\
\hline & & & & Lower & Upper & \\
\hline Sella-Nasion & $68.60 \pm 4.09$ & $71 \pm 3.0$ & -2.39 & -3.175 & -1.612 & $<0.001^{*}$ \\
\hline Sella-Articulare & $34.33 \pm 4.02$ & $32 \pm 3.0$ & 2.33 & 1.565 & 3.101 & $<0.001^{*}$ \\
\hline Articulare-Gonion & $47.51 \pm 6.18$ & $44 \pm 5.0$ & 3.51 & 2.334 & 4.693 & $<0.001^{*}$ \\
\hline Gonion-Menton & $70.28 \pm 5.33$ & $71 \pm 5.0$ & -0.712 & -1.729 & 0.305 & 0.168 \\
\hline Sella-Gonion & $77.09 \pm 8.09$ & $77.5 \pm 7.5$ & -0.402 & -1.948 & 1.142 & 0.606 \\
\hline Nasion-Menton & $115.02 \pm 5.87$ & $112.5 \pm 7.5$ & 2.523 & 1.403 & 3.644 & $<0.001^{*}$ \\
\hline Jarabak \% & $67.07 \pm 6.37$ & $63.5 \pm 1.5$ & 3.570 & 2.354 & 4.787 & $<0.001^{*}$ \\
\hline
\end{tabular}

Table 2: Comparison of mean angular measurements between Nepalese and Caucasian populations

\begin{tabular}{|c|c|c|c|c|c|c|}
\hline \multirow{2}{*}{$\begin{array}{l}\text { Angular Measurements } \\
\text { of Jarabak's analysis }\end{array}$} & \multirow{2}{*}{$\begin{array}{l}\text { Nepalese } \\
\text { (Mean士SD) }\end{array}$} & \multirow{2}{*}{$\begin{array}{l}\text { Caucasians } \\
\text { (Mean } \pm \text { SD) }\end{array}$} & \multirow{2}{*}{ Mean Diff. } & \multicolumn{2}{|c|}{$\mathbf{9 5} \%$ Confidence Interval } & \multirow{2}{*}{ p-value } \\
\hline & & & & Lower & Upper & \\
\hline Saddle Angle & $125.28 \pm 5.97$ & $123 \pm 6.0$ & 2.282 & 1.143 & 3.422 & $<0.001^{*}$ \\
\hline Articular angle & $141.20 \pm 6.14$ & $143 \pm 5.0$ & -1.796 & -2.968 & -0.624 & $0.003^{*}$ \\
\hline Upper Gonial Angle & $52.30 \pm 3.65$ & $53.5 \pm 1.5$ & -1.194 & -1.891 & -0.498 & $0.001^{*}$ \\
\hline Lower Gonial Angle & $72.29 \pm 5.28$ & $72.5 \pm 2.5$ & -0.208 & -1.216 & 0.799 & 0.683 \\
\hline Gonial Angle(Total) & $124.31 \pm 6.59$ & $130 \pm 7.0$ & -5.680 & -6.939 & -4.422 & $<0.001^{*}$ \\
\hline Sum of angles & $390.80 \pm 7.04$ & $396 \pm 6.0$ & -5.194 & -6.539 & -3.850 & $<0.001^{*}$ \\
\hline
\end{tabular}

\section{DISCUSSION}

The study reveals sexual dimorphism within Brahmin groups. The craniofacial structures of Nepalese Brahmin males are larger than Nepalese Brahmin females. This study also reveals ethnic variation. When compared with Caucasian the study reveals that their craniofacial structure is smaller than that of Caucasians.

The anterior cranial base length between Nepalese male and female is statistically significant with Nepalese males having greater mean value of Sella-Nasion compared to females. A shorter anterior cranial base length among Nepalese Brahmin when compared to Caucasians represents a feature of Nepalese Brahmin population. Similar result was found in a different study by Dandajena and Nanda, who reported that anterior cranial base length in blacks is shorter than in Caucasians ${ }^{17}$. Mohammad Khurseed Alam also reported mean anterior cranial base length in Bangladeshis significantly shorter than Caucasians ${ }^{18}$. Thus, a short anterior cranial base length could be a racial feature of Asian population in general.

The mean posterior cranial base length among Nepalese Brahmin males was statistically significant with higher mean value of Sella-Articulare as compared to females. The mean value of posterior cranial base length in Brahmins when compared with Caucasians was found to be higher $(p<0.01)$. This is supported by the evidence that the components of the cranial base differ between populations. Nobuyuki has shown that the anterior cranial base in Japanese was shorter than that in American samples ${ }^{19}$. The posterior cranial base in Japanese was found to be larger than that in Americans. Cranial base length was found to be larger in Australian Aboriginals than in Japanese $\mathrm{e}^{20}$.

The ramus height of Nepalese Brahmin males and females was found to be statistically significant $(p<0.001)$ with Nepalese males having higher value as compared to Nepalese females. The mean value of ramus height was significantly higher $(p<0.001)$ among Nepalese Brahmins as compared to Caucasians. This was in accordance with a similar study done in Bangladeshis ${ }^{18}$. In contrast Mayury Kuramae found no statistical significance between Brazilian black subjectsand Caucasians ${ }^{21}$ making clear that there appears to be variations in craniofacial morphology among different ethnic groups.

The mandibular body length of Nepalese Brahmin males was found to have greater statistical significance compared to the female counterpart. These values obtained are justified by a study done by Gianelley ${ }^{22}$. The mean values of mandibular body length of Nepalese Brahmins and Caucasians are statistically not significant. Similar finding was also demonstrated by Khursheed Alam $^{18}$. 
The posterior facial height of Nepalese Brahmins males and females was not statistically significant, showing the same type of growth pattern. When the mean posterior facial height is compared between Nepalese and Caucasians, the mean value of posterior facial height is not statistically significant $(p>0.05)$, which was in agreement to a study done on Icelandic adults by Berglind Johannsdottir et $a^{23}$.These findings are in contrast to a study done by Livia Maria Andrade de Freitas $^{24}$.

The anterior facial height between Nepalese Brahmins males/females is statistically significant $(p<0.001)$, with Nepalese Brahmin males having higher mean value compared to females. When compared with Caucasians, Nepalese Brahmins had higher mean value of the anterior facial height that is statistically significant $(p<0.001)$. Nepalese Brahmin males had greater mean value of Jarabak ratio compared to females which is in agreement with a similar study done on Brazilian black subjects where the Black girls had smaller total anterior facial height compared to black boys.

Also, the mean value of Jarabak ratio is higher among Nepalese compared to Caucasians. In the same study by Freitas et al, facial height was cephalometrically compared and sexual dimorphism was verified ${ }^{24}$. Mean facial height index among black males and females was statistically not significant. The mean facial height index among white females was higher compared to white males. In the present study the mean value was smaller in girls, which was in contrast to the study done by Coben ${ }^{25}$.

Among the linear dimensions of craniofacial region, all the parameters were found to be smaller in women compared to men. This is consistent with the knowledge that men generally have a larger cranium and a larger mandible than women. Findings concerning gender differences may be explained by the fact that, on average, men have higher masticatory force than women ${ }^{26}$.

Saddle angle (Nasion-Sella-Articulare) of Nepalese Brahmin male and female was not statistically significant. This was in agreement to a similar study done on Danish population ${ }^{27}$. The Nepalese Brahmins had greater mean value of Saddle angle as compared to Caucasians. Increased saddle angle denotes more backward position of the mandible. Saddle angle among Icelandic male and female was in accordance with the present study ${ }^{23}$.
The Nepalese Brahmin females have greater value of Articular angle (Sella-Articulare-Gonial) compared to Nepalese Brahmin males which is in contrast to a similar study done on Brazilian black patient by M. Kuramae et al where the mean value of articular angle was significantly higher among Brazilian males compared to females. When the mean value of articulare angle was compared between Nepalese and Caucasian it was found to be statistically not significant. This was in agreement with study done by Nabeel F Talic et al among Saudis ${ }^{28}$.

The upper gonial angle between Nepalese males and females was statistically not significant. When compared to Caucasians, the mean value is greater than that of Nepalese Brahmins. Difference in the gonial angle of the two sexes has been found in the previous studies, and the general trend was that the gonial angles in males are greater than those measured in females ${ }^{29}$. Usually the mean angle is $3-5^{\circ}$ greater in males ${ }^{28}$. However, the present study showed no correlation between genders with gonial angle, and this is in agreement with Raustia $\mathrm{AM}$ and Salonen mam and Ceylan et $\mathrm{al}^{30,31}$.

The mean value of lower gonial angle (Nasion-GonionMenton) when compared between Nepalese Brahmin males/females was statistically significant with a greater mean value among females compared to males. This was in accordance to a similar study on Saudis, with distinct male and female lower gonial angle values ${ }^{28} \mathrm{~A}$ larger gonial angle indicates vertical growth change whereas a smaller lower gonial angle relates to sagittal growth. The mean value was not statistically significant when compared between Nepalese and Caucasians.

Total gonial angle is the sum of upper and lower gonial angles. Nepalese Brahmin females had higher mean value compared to Brahmin males. The mean value of Nepalese was lower compared to Caucasians. A large angle among Caucasians indicates tendency to posterior or clockwise rotation of mandible with condylar growth directed posteriorly.

The mean value of sum of angles among Nepalese Brahmins was significantly higher $(p<0.001)$ for females compared to males. In contrast Nabeel F Talic et al. found no statistical significance in the Saudi sample when compared between the sexes ${ }^{28}$. The Caucasians had significantly higher $(p<0.001)$ mean value compared to Nepalese. In contrast, the mean value of sum of angles was not statistically significant among Brazilian black subjects when compared to Caucasians ${ }^{21}$. 


\section{CONCLUSION}

The study revealed significant gender and ethnic variations in craniofacial structures. This degree of difference justified the idea that a single standard of facial esthetics should not be applied to all racial and ethnic groups. The findings of this study highlight the fact that Brahmin population is significantly different from Caucasian population and thus, require a separate set of cephalometric norms for the purpose of diagnosis

\section{REFERENCES}

1. Broadbent $\mathrm{BH}$. A new $\mathrm{x}$-ray technique and its application to Orthodontia. The Angle Orthodontist. 1931; 1(2):45-66. [Full Text]

2. Bishara SE, Fernandez AG. Cephalometric comparisons of the dentofacial relationships of two adolescent populations from lowa and Northern Mexico. American Journal of Orthodontics and DentofacialOrthopedics. 1985; 88(4):314-22. [DOI]

3. Wu J, Hägg $U$, Rabie ABM. Chinese norms of McNamara's cephalometric analysis. The Angle Orthodontist. 2007;77(1):12-20.[DOI]

4. Downs WB. Variations in facial relationships: Their significance in treatment and prognosis. American Journal of Orthodontics and DentofacialOrthopedics. 1948;34(10):812-40.[DOI]

5. Tweed $\mathrm{CH}$. The Frankfort-Mandibular Incisor Angle (FMIA) In Orthodontic Diagnosis, Treatment Planning and Prognosis. The Angle Orthodontist. 1954;24(3):121-69.[Full Text]

6. Cooke MS, Wei SH. A comparative study of southern Chinese and British Caucasian cephalometric standards. The Angle Orthodontist. 1989;59(2):1318.[PubMed]

7. Yeong P, Huggare J. Morphology of Singapore Chinese. The European Journal of Orthodontics. 2004;26(6):605-12.[DOI]

8. Ajayi EO. Cephalometric norms of Nigerian children. American Journal of Orthodontics and DentofacialOrthopedics. 2005;128(5):653-6. [DOI]

9. Wu J, Hägg U, Rabie ABM. Chinese norms of McNamara's cephalometric analysis. The Angle Orthodontist. 2007;77(1):12-20.[DOI]

10. Nanda R, Nanda RS. Cephalometric Study of the Dentofacial Complex of North Indians. The Angle Orthodontist. 1969;39(1):22-8.[PubMed]

11. Gleis R, Brezniak N, Lieberman M. Israeli cephalometric standards compared to Downs and orthodontic treatment planning. Hence it would be preferable to use specific Brahmins norms, for each gender of Nepali population.

This study done inside Kathmandu valley may not represent the whole of Brahmin population of Nepal. Therefore, it is recommended that cephalometric studies examining Nepalese Brahmin samples from different parts of Nepal can better verify the findings presented in this study.

and Steiner analyses. The Angle Orthodontist. 1990;60(1):35-40.[PubMed]

12. Jarabak J R, Fizzell J A. Technique and treatment with lightwire edgewise appliance. C V Mosby, St. Louis.1972.[Full Text]

13. Maple JR et al. A comparison of providers' and consumers' perceptions of facial-profile attractiveness. American Journal of Orthodontics and DentofacialOrthopedics. 2005;128(6):690-6. [DOI]

14. Franklin J. Radiographic Phenomena In Cephalometric Roentgenography. The Angle Orthodontist. 1957;27(3):162-70.[Full Text]

15. Downs WB. Analysis of the dentofacial profile. The Angle Orthodontist. 1956;26(4):191-212. [Full Text]

16. Visser H, Rödig T, Hermann K-P. Dose reduction by direct-digital cephalometric radiography. The Angle Orthodontist. 2001;71(3):159-63.[PubMed]

17. Dandajena TC, Nanda RS. Bialveolar protrusion in a Zimbabwean sample. American Journal of Orthodontics DentofacialOrthopedics. 2003;123(2):133-7.[DOI]

18. Alam M. K. et al.Determining Cephalometric Norms for Bangladeshi Adults Using Bjork-Jarabak's Analysis.International Medical Journal. 2012; 19(4): 329-32.[Link]

19. N.Ishi et al. Morphological differences in the craniofacial structure between Japanese and Caucasian girls with Class II division 1 malocclusion. European Journal of Orthodontics. 2002;24(1): 6167.[DOI]

20. Kasai K, Richards LC, Brown T. Comparative study of craniofacial morphology in Japanese and Australian Aboriginal populations. Human Biology. 1993; 65(5): 821-34.[PubMed]

21. M.Kuramae et al.Jarabak 's Cephalometric Analysis of Brazilian Black Patients. Braz. Dent J. 2007;18(3)25862. [DOI]

22. Gianelly AA. Age and sex cephalometric norms. American Journal of Orthodontics and 
DentofacialOrthopedics. 1970; 57(5): 497-501. [DOI]

23. BerglindJohannsdottir et al. Craniofacial morphology of Icelandic adults. European Journal of Orthodontics. 2006;26(3): 245-250.[DOI]

24. De Freitas LM et al. Facial height comparison in young white and black Brazilian subjects with normal occlusion. American Journal of Orthodontics and DentofacialOrthopedics. 2007;131(6): 706.e16.[DOI]

25. Coben SE. The Integration of facial skeletal variants. American Journal of Orthodontics and DentofacialOrthopedics. 1955; 41(6): 407-34. [DOI]

26. Bakke $M$ et al. Unilateral isometric bite force in 8-68 year old women and men related to occlusal factors. European Journal of Oral Sciences. 1990; 98(2):14958.[DOI]
27. Ingerslev $\mathrm{CH}$, Solow B. Sex differences $n$ craniofacial morphology. ActaOdontogicaScandinavica. 1975; 33(2): 85-94.[DOI]

28. Nabeel F Talic et al.Cephalometric Measurements of a Saudi Adult Sample.Pakistan Oral \& Dental Journal. 2009; 29(2):281-6. [Full Text]

29. Jensen $E$, Palling M. The gonial angle. American Journal of Orthodontics and DentofacialOrthopedics. 1954;40: 120-33.[DOI]

30. Raustia AM et al. Gonial angle, condylar and ramus height of the mandible in complete denture wearersa panomaric radiograph study. J Oral Rehab. 1997; 24(7):512-26.[DOI]

31. Ceylan $C$ et al. Changes in mandibular angle in the dentulous and edentulous states. J prosthet. Dent. 1998; 80(6): 680-4. [DOI] 